\title{
Prognostic Factors of Non-Traumatic Small Bowel Perforation Peritonitis: A Multicenter Study in North Benin
}

\author{
Montcho Adrien Hodonou ${ }^{1, ~ *, ~ S a l a k o ~ A l e x a n d r e ~ A l l o d e ~}{ }^{1}$, Bio Tamou-Sambo' ${ }^{1}$, Djifid Morel Seto ${ }^{1}$, \\ Mahougnon Hermann Houegnanou ${ }^{1}$, Francis Moïse Dossou ${ }^{2}$ \\ ${ }^{1}$ Department of Surgery and Specialities, Faculty of Medicine, University of Parakou, Teaching Hospital of Parakou, Parakou, Benin \\ ${ }^{2}$ Department of General Surgery, Faculty of Health Science, University of Abomey Calavi, Teaching Hospital of Ouémé, Porto-Novo, Benin
}

Email address:

hodasm98@gmail.com (M. A. Hodonou)

${ }^{*}$ Corresponding author

\section{To cite this article:}

Montcho Adrien Hodonou, Salako Alexandre Allode, Bio Tamou-Sambo, Djifid Morel Seto, Mahougnon Hermann Houegnanou, Francis Moïse Dossou. Prognostic Factors of Non-Traumatic Small Bowel Perforation Peritonitis: A Multicenter Study in North Benin. Journal of Surgery. Vol. 6, No. 1, 2018, pp. 29-32. doi: 10.11648/j.js.20180601.16

Received: December 24, 2017; Accepted: January 15, 2018; Published: February 19, 2018

\begin{abstract}
Objective: Identify the factors affecting the non-traumatic intestinal perforations peritonitis outcome. Methods: This was a retrospective study over a period of 30 months $\left(1^{\text {st }}\right.$ January $2014-30^{\text {th }}$ June 2016$)$, which took place in four hospitals in northern Benin, including three district hospitals and one teaching hospital. The study population consisted of patients operated for generalized acute peritonitis. The inclusion criteria were: peroperative confirmation of the non-traumatic ileal perforation and the existence of a complete medical record in relation to the variables studied. Results: We collected 121 cases of non-traumatic ileal perforation peritonitis with a total of 447 cases of generalized acute peritonitis; the non traumatic ileal perforation peritonitis frequency was $27.1 \%$. Ninety-nine files met the inclusion criteria. The mean age was $17 \pm 12$ years with extremes of 2 and 60 years. The sex ratio was 2.4. The predictive factors were: age ( $p 0.00)$, consultation time $(p 0.03)$, surgical time $(p 0.02)$, amount of peritoneal fluid ( $p 0.001)$, perforation number $(p 0.0009)$, surgical technique $(p 0.0003)$ and postoperative complications such as digestive fistula $(p 0.001)$ and postoperative peritonitis $(p 0.04)$. Conclusions: At the end of our study, the factors of bad prognosis identified were the age, the time of consultation, the time of surgery, the quantity of peritoneal fluid. Some postoperative complications may cause death.
\end{abstract}

Keywords: Non-Traumatic Intestinal Perforation, Prognostic Factor, Age, Multiple Perforations, Digestive Fistula

\section{Introduction}

The small bowel perforation peritonitis is one of the main causes of generalized acute peritonitis in developing countries [1]. It is a medical and surgical emergency. Among these ileal perforations, typhoid etiology is the most represented in developing countries [2]. Their prognosis remains poor, justified by high morbidity and mortality rates. In fact, this morbidity rate was $46 \%$ in Niger, 2001 [3], mortality rate, $18 \%$ in Mali, 2009 [1] and 20\% in Democratic Congo, 2014 [4]. The aim of this study was to identify the factors which influence the prognosis of peritonitis by non traumatic ileal perforation as they are managed in hospitals in north eastern Benin.

\section{Framework and Method}

\subsection{Type of Study}

This retrospective study over a period of 30 months (1st January 2014 - 30th June 2016) took place in 04 hospitals in north eastern Benin. These included the Parakou University Hospital Center (CHUP) and three district hospitals (Saint Martin Hospital Papané, Evangelical Hospital Bembéréké and Sounon Séro Hospital Nikki). In the Benin health system, the district hospital is the first reference level for the peripheral health units of a defined geographical area called the health zone, whereas the departmental hospital centers represent the second reference level for several district hospitals in a defined geographical area. 


\subsection{Study Population}

It was patients operated for generalized acute peritonitis.

\subsection{The Inclusion Criteria}

The inclusion criteria were the intraoperative confirmation of the non-traumatic ileal perforation attested by the operative report.

The judgment criterion guiding the choice of the variables of the study was underpinned by the definition of the prognosis. The prognosis is the prediction of the probable evolution of a disease. It is based on the knowledge of the usual evolution of the disease that combines with the consideration of factors that can influence this evolution. The variables were therefore epidemiological, diagnostic, therapeutic and progressive in the early postoperative period. This period covers 30 days after surgery [5]. Among these variables, the consultation time was the time that elapses between the onset of symptoms and the arrival of the patient in consultation; while the time of surgery covers the period from admission to the entrance to the operating room. Postoperative complications were grouped according to the Clavien-Dindo-Strasberg classification, which distinguishes 5 grades [6]. Grade I concerns any undesirable postoperative event that does not require treatment. Grade II complications require medical treatment while those in Grade III require surgical, endoscopic or radiological treatment. Grade IV includes life-threatening complications that require intensive care. Grade V corresponds to death. The sepsis severity was evaluated according to the score of World Society of Emergency Surgery (WSES) [7]: WSES sepsis severity score for patients with complicated Intra-abdominal infections (Range: 0-18): Clinical condition at the admission: Severe sepsis (acute organ dysfunction) at the admission 3 score; septic shock (acute circulatory failure characterized by persistent arterial hypotension. It always requires vasopressor agents) at the admission 5 score. Setting of acquisition: Healthcare associated infection 2 score. Origin of the peritonitis: Colonic nondiverticular perforation peritonitis 2 score; Small bowel perforation peritonitis 3 score; Diverticular diffuse peritonitis 2 score; Post-operative diffuse peritonitis 2 score. Delay in source control: Delayed initial intervention [Preoperative duration of peritonitis (localized or diffuse) $>24 \mathrm{~h}$ )] 3 score. Risk factors: Age $>70$ years 2 score; Immunosuppression (chronic glucocorticoids, immunosuppresant agents, chemotherapy, lymphatic diseases, virus) 3 score. When the total score is under or 3, the severity is low; score 4-6: moderate severity; score upper or equal 7 , the severity is high associated with poor prognosis. The chi-square test was used to search for statistical relations, the threshold of significance being fixed at 5\%.

\section{Results}

\subsection{Socio-Demographic Characteristic and Morbi- Mortality}

One hundred twenty one non-traumatic ileal perforation peritonitis cases were collected from a total of 447 acute generalized peritonitis with a frequency of $27.1 \%$. Ninetynine patients met the inclusion criteria. The average age was $17 \pm 12$ years with extremes of 2 years and 60 years. Children (0 to 15 years) accounted for $69.7 \%$ (69/99 patients). The sample included 70 men for 29 women, corresponding to a sex ratio (M/F) of 2.4. Schoolchildren, pupils and students constituted the most affected layer, ie $55.6 \%$ (55/99 cases). The average consultation time was 72 hours. Probably typhic ileal perforation was the leading cause at $93.9 \%$ (93/99 cases) followed by strangulated hernia of the small bowel with necrosis $(6.1 \%)$ (6/99 cases). The morbidity was $62.6 \%$ (62 / 99cas) dominated by surgical site infections with $45.5 \%$ (45/99). The mortality was $11.1 \%$ (11/99 cases). Table $\mathrm{n}^{\circ} 1$ shows the postoperative complications grouped according to the Clavien-DindoStrasberg classification.

Table 1. Postopérative Complications according to Clavien-Dindo-Strasberg classification.

\begin{tabular}{lll}
\hline & Number & Percentage (\%) \\
\hline Grade II & 16 & 16,2 \\
Anemia & 1 & 1 \\
Acute edema of lungs & 1 & 1 \\
Shock & 1 & 1 \\
Hypokalemia & 1 & 1 \\
Sepsis & & \\
Grade III & 45 & 45,5 \\
Surgical site infection & 9 & 9,1 \\
Digestive fistula & 7 & 7,1 \\
Evisceration & 5 & 5,1 \\
Postoperative peritonitis & 1 & 1 \\
Occlusion on bridle & & \\
Grade IV & 2 & 2 \\
Acute kidney failure & & \\
Grade V & 11 & 11,1 \\
Death & & \\
\hline
\end{tabular}

\subsection{Prognostic Factors}

\subsubsection{Age and Sex}

Postoperative complications were more common in children and adolescents $(41 / 62$ or $66.1 \%)$ and in the male sex $(45 / 62$ or $72.6 \%)$. Of the 11 deceased patients, 7 were children aged 0 to 5 years. Age influenced mortality $(p=0$, $00)$. Sex had no influence on mortality $(\mathrm{p}=0.77)$.

\subsubsection{Time of Consultation (Admission) and Delay of Surgical Intervention}

The average consultation time was 72 hours. Nine of the 11 deceased patients had been seen more than 72 hours after the symptoms onset $(\mathrm{p}=0.03)$.

There were 10 deaths in the group of patients operated after a preoperative resuscitation of more than 6 hours against a single death of the group of patients operated within 6 hours of admission.

\subsubsection{Intraoperative Findings}

Of 58 patients in whom the peritoneal fluid was fecaloid or purulent, 43 or $74.1 \%$ had a surgical site infection. In the 11 deceased patients the fluid was fecaloid or purulent.

The amount of peritoneal fluid aspirated was associated 
with mortality $(p=0.001)$. Indeed, when this quantity is greater than $1000 \mathrm{ml}$ (14 patients), the mortality was high ( $50 \%$ or 7 patients). It was also related to the occurrence of acute renal failure ( 2 cases).

For the 31 patients in whom the surgical technique chosen was a resection-anastomosis due to multiple perforation and existence of preperforative site, 8 had presented a digestive fistula.

Mortality also increased with the number of perforations. In fact, of the 17 patients who had just two perforations, 2 died; while, of the 7 patients who presented more than 2 perforations site, 4 deaths were noted ( $\mathrm{p}$ 0.0009).

\subsubsection{Surgical Techniques}

The perforations were repaired by excision-suture in $67.7 \%$ of cases, resection-anastomosis in $31.3 \%$ of the cases and resection-ileostomy, $1 \%$. The results of the different operative techniques with their complications and death are shown in Tables $n^{\circ} 2$ and 3.

Table 2. Surgical techniques influency on the morbidity.

\begin{tabular}{lllll}
\hline Early Operative Follow-up & & & & \\
\hline Surgical Techniques & Complicated Cases & & Non-Complicated Cases & Total \\
\hline & n & \% & n & \\
\hline Resection - anastomosis & 27 & 87,1 & 4 & 31 \\
Rsection- ileostomy & 1 & 100 & 0 & 1 \\
Excision- suture & 34 & 50,7 & 33 & 0,003 \\
\hline
\end{tabular}

Table 3. Influency of surgical techniques on mortality.

\begin{tabular}{lllll}
\hline Mortality & & & & \\
\hline Surgical technique & N & Yes \% & No n & Total \\
\hline Resection-anastomosis & 8 & 29,6 & 19 & 27 \\
Resection-ileostomy & 1 & 100 & 0 & 1 \\
Excision-suture & 2 & 5,9 & 32 & 0,0003 \\
\hline
\end{tabular}

Postoperative complications and deaths.

Some postoperative complications worsened the patient prognosis who died. It was the digestive fistula $(p=0.001)$, postoperative peritonitis $(\mathrm{p}=0.04)$.

\subsubsection{Prognosis Scores}

The occurrence of death increased significantly with the severity of infection according to the WSES sepsis severity score $(p=0.005)$. Indeed for a score less than or equal to 3 , there was $8 \%$ of deaths, when this score was between 4 and 6 the death rate was $19.2 \%$ and from 7 , it reached $36.4 \%$

\section{Discussion}

Non traumatic intestinal perforation Peritonitis is a multivisceral repercussion disease with a high morbidity and mortality rate. This rate is still high $(62.6 \%)$ and falls within the range of 42 to $80 \%$ reported in the literature $[8,9,10]$. This morbidity and mortality is linked to poor prognosis factors such as age. Ademola et al. in Nigeria [11] as well as Coulibaly et al. in Mali [12] had already reported this influence of age on mortality with respectively $p=0.026$ and $\mathrm{p}<0.05$. We found that among our 11 deceased patients 7 were children aged 0 to 5 years ( $p 0.00)$. Extreme ages are a factor of poor prognosis in case of peritonitis.

The delay in the consultation (average of 72 hours in our series) can be considered as a specific prognostic factor of the developing countries, related to the lack of financial means. Wandering of diagnosis in peripheral health units is also incriminated. In addition to these aspects, there is the cultural phenomenon of the long stay in the traditional practitioner. This delay exposes the peritoneal cavity to massive and prolonged flooding of the infected contents of the perforated small bowel. This promotes the spread of the infection responsible for severe sepsis. We have shown a significant relationship between the consultation time and the mortality $(\mathrm{p}=0.03)$. Indeed, of the 11 patients who died, 9 had consulted beyond 72 hours. Studies have already noted that delay in consultation is a factor of poor prognosis [13, 14]. Another factor of poor prognosis is the delay in the management of the operation. Muhammad L et al. reported it in their study in $2009(\mathrm{p}=0.04)$ [8]. This delay in our environment can be explained by the precarious financial resources of patients. They must pay both prescriptions, from surgeon and the anesthesiologist before being admitted into the operating room. This double delay (consultation and operative management) weakens the patient's resistance and exposes to complications. We observed that mortality increases with the number of perforations ( $p$ 0.0009). The same observation was made by Kenneth et al. [15] with $p=0.00$. These perforations are probably the cause of an important third sector that adds to severe sepsis, creates a state of mixed shock, responsible of polyvisceral failure. This, also justifies that, more the intraperitoneal fluid is important, the mortality is higher $(\mathrm{p}=0.001)$. All the deceased patients had faecaloid or purulent fluid. Our observations are similar to those of Wacha et al. [16] who noted that the fecaloid aspect influences mortality.

Several operating techniques are described in the literature. Their choice depends on many parameters namely the general condition of the patient, the degree of contamination of the abdominal cavity, the state of the intestine (ischemia, presence of pre-perforative sites) and the number of perforation holes. Although there is no unanimity about an operative technique, many authors agree on an intestinal 
resection in case of multiple perforations. Most of us performed bowel resection followed by immediate anastomosis. This surgical technique had a significant influence on mortality in our study (p 0.0003). We must, then review our selection criteria and improve the operative technique in order to reduce mortality. However, despite high mortality after immediate resection-anastomosis in their series, Ademola et al. [11] and Edino ST et al. [17] do not show significant influence of this technique on mortality with respectively $\mathrm{p}=0.59$ and $\mathrm{p}>0.05$.

Digestive fistula is a very sinister complication [18]. It aggravates the precarious state of a patient already weakened by hydro-electrolytic and infectious disorders. Under these conditions, its influence on mortality was significant $(\mathrm{p}=$ 0.001). In their study on the prognostic factors of ileal perforations, Muhammad et al. [8] had previously noted that digestive fistula was a factor of poor prognosis. Evisceration had no influence on mortality in our series $(p=0.8)$. A result contrary to ours has been reported in Asian and African studies with respective $p$ values of 0.001 and $0.038[8,11]$.

All of these parameters seem to be consistent with the WSES sepsis severity score. Indeed we observed that the mortality increased with the elevation of the WSES score ( $p=$ 0.005). The infection that accompanies peritonitis needs to be treated early and aggressively.

\section{Conclusion}

This study allowed us to highlight predictive factors of poor prognosis which are: extreme ages of life, delay in consultation, a long period of admission to the operating room, the amount of peritoneal fluid beyond $1000 \mathrm{ml}$; fecaloid or purulent appearance of the fluid and multiple perforations. The surgical technique remains a prognostic factor because of its choice, depends the postoperative complications of which the most serious are the digestive fistula and postoperative peritonitis.

\section{References}

[1] Niangaly A, Seydou D, Nianguiry K, Coulibaly S, Dembélé $\mathrm{K}$, Mamadou D. Les péritonites par perforation intestinale dans la région de Sikasso. Rapport final de l'Institut National de Recherche en Santé Publique (INRSP): Mali; 2009.

[2] Ouangre E, Zida M, Bonkoungou PG, Sanou A, Traore SS. Les péritonites aigües généralisées en milieu rural au Burkina Faso: à propos de 221 cas. Rev. Cames Santé. Décembre 2013; 1 (2):75-9.

[3] Harouna YD, Abdou I, Saidou B, Bazira L. Les péritonites en milieu tropical: Particularités étiologiques et facteurs pronostiques actuels - A propos de 160 cas. Médecine d'Afrique Noire. 2001; 48 (3):103-6.

[4] Alumeti MD, Luhiriri NL, Nfundiko K, Iteke FR, Cikwanine
B, Bafunyembaka AM et al. Problématique de la perforation iléale au décours des infections à salmonella. The 2014 ICART Symposium: 24-5.

[5] Bouillot JL, Aouad K. traitement chirurgical des complications des colostomies. Encyclo Med Chir (ed scientifiques et médicales Elsevier SAS, Paris, tous droits réservés), techniques chirurgicales, appareil digestif; 2002: 540-5.

[6] Dindo D, Demartines N, Clavien P. Classification of Surgical Complications. A New Proposal With Evaluation in a Cohort of 6336 Patients and Results of a Survey. Ann Surg. 2004; 240 (2): 205-13

[7] Sartelli M, Abu-Zidan FM, Catena F, Griffiths EA, Di Saverio S. et al. Global validation of the WSES Sepsis Severity Score for patients with complicated intra-abdominal infections: a prospective multicentre study (WISS Study). World Journal of Emergency Surgery. 2015; 10 (61): pp 8.

[8] Muhammad L, Shams NA, Jahanzaib H, Khalid AM. Prognostic factors in typhoid enteric perforation. Pakistan Journal of Surgery. 2009; 25 (2):101-5.

[9] Arshad HA, Faisal GS, Sarfraz A. Demographic and surgical evaluation of typhoid ileal perforation. $\mathrm{J}$ ayub med coll abbottabad. 2012; 24 (3-4):87-9.

[10] Purujit C. Choice of Surgical Procedures in Enteric Fever: A Study. Int J Health Sci Res. 2014; 4 (8):87-92.

[11] Ademola OT, Amarachukwu E, Oludayo S, Olowookere S. Predictors of mortality in children with typhoid ileal perforation in a Nigerian tertiary hospital. Pediatric Surg Int 2014; $10 \mathrm{p}$.

[12] Coulibaly Y, Togo AA, Keita M et al. Péritonites typhiques chez l'enfant: Evaluation de la morbi-mortalité au CHU Gabriel Touré, Bamako. Mali Medical 2013; 28 (3):24-7.

[13] Kassegné I, Kanassoua KK, Sewa EV, Tchangai B, Samiani $\mathrm{DM}$, Ayité $\mathrm{AE}$ et al. Péritonite aigüe généralisée au CHU de Kara, RAMUR, SARANF Stauts 2013; 18 (2).

[14] Allode SA, Mensah E, Dossou F, Savi De Tovè S, Bori Bata $\mathrm{K}$, Gandaho $\mathrm{P}$, Bagnan KO. Aspects épidémiologiques, cliniques et paracliniques des péritonites aigües généralisées au CHDUP. Le Bénin Médical $\mathrm{N}^{\circ} 38$.

[15] Kenneth A, Martin N, Emmanuel O. Prevalence, Morbidity, and Mortality Patterns of Typhoid Ileal Perforation as Seen at the University of Nigeria Teaching Hospital Enugu Nigeria: An 8-year Review. World J Surg 2014; 38: 2514-2518.

[16] Wacha, Hau T, Dittmer R et al. Risk factors associated with intraabdominal infections: a prospective multicenter study. Langenbeck's Arch Surg. 1999; 384:24-32.

[17] Edino ST, Yakubu AA, Mohammed AZ, Abubakar IS. Prognostic Factors in Typhoid heal Perforation: A Prospective Study of 53 Cases. Journal of the national medical association 2007; 99 (9): 1042-5.

[18] Wani RA, Fazl QP, Nadeem AB, Wani MA, Tasaduq HB, Fowzia F. Nontraumatic terminal ileal perforation. World Journal of Emergency Surgery. 2006; (1):4p. 